\title{
Higher reoperation rate following cervical disc replacement in a retrospective, long-term comparative study of 715 patients
}

\author{
Martin Skeppholm ${ }^{1,2} \cdot$ Thomas Henriques $^{2}$. Tycho Tullberg ${ }^{3}$
}

Received: 8 April 2017/Revised: 27 June 2017/Accepted: 11 July 2017/Published online: 17 July 2017

(c) The Author(s) 2017. This article is an open access publication

\begin{abstract}
Purpose To evaluate rates of secondary surgical interventions in a cohort treated with fusion (ACDF), artificial disc replacement (ADR) or a posterior surgical procedure (PP) because of a cervical degenerative pathology.

Methods 715 patients treated with any primary cervical surgical intervention between the years 2000 and 2010 were retrospectively evaluated regarding frequency of secondary surgery between the years 2000 and 2015, thus giving a follow-up time of minimum 5 years. Reasons for secondary surgery as well as choice of new intervention were evaluated. Data were collected from a single-center setting.

Results Follow-up rate was $94 \% .79$ (11\%) patients in total underwent a new operation during follow-up. 50/504 (10\%), 27/172 (15\%), and 2/39 (5\%) of the patients had a second surgical intervention in the ACDF, ADR, and PP groups, respectively. There was a statistically significant higher rate of repeated surgery in the ADR group compared to the ACDF group, OR 1.7 (CI 1.06-2.8), $p=0.03$. Risk for repeated surgery at index level was even higher for ADR, OR 5.1 (CI 2.4-10.7), $p<0.001$. Reoperation rate because of ASD in the whole cohort did not differ between ACDF and ADR groups, $p=0.40$.
\end{abstract}

Martin Skeppholm

martin.skeppholm@rkc.se

1 Karolinska Institute, Department of Learning, Informatics, Management and Ethics (LIME), Medical Management

Centre, Health Economics and Economic Evaluation Research Group, Tomtebodavägen $18 \mathrm{~A}$,

SE-171 77 Stockholm, Sweden

2 Center for Spine Surgery in Stockholm, Södra Fiskartorpsvägen 15 H, 11485 Stockholm, Sweden

3 Stockholm Spine Center, Löwenströmska Sjukhuset, 19489 Upplands Väsby, Sweden
Conclusion The group initially treated with artificial disc replacement showed higher rate of reoperations and more implant-related complications. In this cohort, artificial disc replacement was not protective against reoperation because of adjacent segment pathology.

Keywords Reoperation rate $\cdot$ Secondary surgery $\cdot$ Cervical spine

\section{Introduction}

Surgical treatment for cervical radiculopathy can be performed with different techniques, approaches, and with a growing number of different implants. One of the most used techniques is anterior cervical decompression and fusion (ACDF) for the last decades, and there has been an ongoing debate concerning possible disadvantages and side effects following this technique. Several previous publications proposing that decreased motion at a fused level can accelerate degenerative changes at adjacent level, adjacent segment disease (ASD), could have been contributing and invigorative factors for the development of artificial disc replacement (ADR) devices [1-5]. The intention of ADR is to maintain motion at the operated level and thereby avoiding increased stress at the adjacent level, which theoretically could precipitate ASD. Several investigational device exemption studies (IDE) with RCT designs comparing ACDF and ADR have shown higher frequencies of secondary surgeries after ACDF, mostly because of ASD and pseudarthrosis [6-9]. Other studies with data from larger cohorts outside the IDE studies have not been able to substantiate this $[10,11]$. With the introduction of new surgical techniques and implants, there is also a risk for development of new side effects and 
complications. Previously described advert events after treatment with ADR are implant instability and migration, heterotopic bone formation, and implant wear [12-16]. The aim of this retrospective study was to compare frequencies of secondary surgery after different primary interventions for cervical degenerative spine pathology. The reasons of secondary surgery and choice of surgical method for the secondary interventions were also assessed.

\section{Patients and methods}

715 patients registered as a primary cervical surgical procedure in the years 2000-2010 were included. All patients were treated at one single surgical setting, highly specialized in degenerative spine disorders. Average age was 47 years and $49 \%$ were women. For this study, the surgical procedures were classified into the three subgroups: anterior cervical decompression and fusion (ACDF), artificial disc replacement (ADR), and posterior procedures (PP). There were no statistical significant differences in age, gender, or number of surgical levels between the groups (Table 1). $504(70 \%)$ of the surgical interventions were ACDFs, 172 (24\%) were ADRs, and 39 (6\%) were posterior procedures $(\mathrm{PP})$ including laminectomy or foraminotomy without instrumentation. 120 patients $(17 \%)$ were classified with the diagnose myelopathy and were all treated with ACDF or a PP. Of the remaining 595 patients, the indication for surgery was radiculopathy with at least 3 months of duration before surgery. The choice of procedure was associated with MRI pathology and grade of degeneration. In general, an anterior root affection was associated with a decision to perform an ACDF or ADR, while a posterior pathology was performed with a PP. Patients with more advanced degenerative changes were more unlikely to be treated with ADR as a motion sparing concept, theoretically, is more dependent on normal surrounding functional structures, e.g., uncovertebral joints and facet joints. ACDF was performed with iliac crest bone graft or cage with additional plating in most cases. When cage was used, it was filled with bone harvested during decompression (osteophytes and/or uncovertebral joints). ADR was performed with the Discover ${ }^{\mathrm{TM}}$ artificial disc (DePuy Spine) or the Prestige ${ }^{\mathrm{TM}}$ LP cervical disc (Medtronic). The distribution of different surgical concepts is presented in

Table 1 Baseline data of mean age (SD), distribution of gender, and number of surgical levels between ACDF, ADR, and PP groups

\begin{tabular}{llll}
\hline & $\operatorname{ACDF}(n=504)$ & $\operatorname{ADR}(n=172)$ & $\operatorname{PP}(n=39)$ \\
\hline Age & $47.3(3.1)$ & $46.6(4.5)$ & $47.4(9.3)$ \\
Men/female & $258 / 246$ & $87 / 85$ & $20 / 19$ \\
Levels $1 / 2 / 3 / 4$ & $319 / 176 / 9 / 0$ & $117 / 54 / 1 / 0$ & $21 / 8 / 6 / 4$ \\
\hline
\end{tabular}

Table 2. In a more detailed analysis of surgical levels between the ACDF and ADR groups, there was a statistical significant difference in the $\mathrm{C} 3-\mathrm{C} 5$ level group but not in any other combination of levels (Table 3). Diagnosis and type of operation were registered with separate codes. Diagnoses were classified as radiculopathy because of herniated disc or foraminal stenosis with or without myelopathy. Patients seeking with new symptoms after surgery were evaluated with flexion/extension plain X-ray, MRI, and CT to determine if the problem was associated with ASD with root affection, pseudarthrosis (ACDF) or instability/migration (ADR). In cases of uncertainty regarding motion in an ACDF or instability of an ADR, a complimentary 3D CT with high accuracy for detecting small movements was performed. This analysis was part of another research project and could only be done at the initial setting [17]. Pseudarthrosis, or non-healing, was defined as visible motion in any of the above-mentioned modalities. Instability in ADR was defined as a visible migration compared to initial postoperative $\mathrm{X}$-ray, or detectable motion between in any of components of the ADR relative to the surrounding vertebrae. The first follow-up was based on a code for secondary intervention. Patients coded for any cervical reoperation at the initial setting in the years 2000-2015 were registered and included in a second analysis, and thus, the follow-up time for the initially included group was at least 5 years. For the second step follow-up, patients without reoperation code at the initial setting were initially contacted via letter in which they were asked about secondary cervical surgery at other settings. If no answer was received, we made attempts to establish contact via telephone. In those cases, where patients could confirm secondary cervical spine surgery at other settings, copies of medical records were commissioned and reviewed (Fig. 1). From this material, we could analyze reasons for reoperation, time interval between the surgeries, and type of secondary surgery. The PP group was excluded from comparative statistical analysis regarding reoperations as the group was smaller and contained more heterogeneity in interventions than the ACDF and ADR groups. All patients who had undergone surgery at other settings were asked for permission before commissioning of their medical records. The study was approved by the regional ethics committee in Stockholm (2015/2327-31/2).

\section{Statistics}

Descriptive statistics was used for patient characteristics and baseline data. Adjustment for differences between groups in baseline variables was not performed. A $2 \times 2$ contingency table was used to calculate differences in reoperations between groups. Chi-square test and Fisher's exact test were used for categorical data and independent 
Table 2 Distribution of different interventions (\% of all in the group), number of surgical levels, and rate of reoperations (\% of all in the group) after intervention in the $\mathrm{ACDF}, \mathrm{ADR}$, and PP groups respectively

\begin{tabular}{llclr}
\hline Group & Intervention & Levels $1 / 2 / 3 / 4$ & Reoperations \\
\hline ACDF $(n=504)$ & Fusion w plating & $464(93)$ & $279 / 176 / 9 / 0$ & $46(10)$ \\
& Fusion wo plate & $40(7)$ & $40 / 0 / 0 / 0$ & $4(10)$ \\
ADR $(n=172)$ & Discover disc & $151(88)$ & $96 / 54 / 1 / 0$ & $24(16)$ \\
& Prestige LP disc & $21(12)$ & $21 / 0 / 0 / 0$ & $3(15)$ \\
$\operatorname{PP}(n=39)$ & Laminectomy & $21(54)$ & $6 / 6 / 5 / 4$ & $2(10)$ \\
& Foraminotomy & $18(46)$ & $15 / 2 / 1$ & $0(0)$ \\
\hline
\end{tabular}

Table 3 Distribution of surgical levels between the ACDF and ADR groups, respectively

\begin{tabular}{lccc}
\hline Levels & ACDF $[n=504(\%)]$ & ADR $[n=172(\%)]$ & $p$ level \\
\hline C3-C4 & $9(2)$ & $2(1)$ & 0.74 \\
C4-C5 & $12(2)$ & $6(3)$ & 0.58 \\
C5-C6 & $151(30)$ & $58(34)$ & 0.39 \\
C6-C7 & $144(29)$ & $50(29)$ & 0.92 \\
C3-C5 & $12(2)$ & $0(0)$ & 0.04 \\
C4-C6 & $30(6)$ & $9(5)$ & 0.85 \\
C5-C7 & $134(27)$ & $45(26)$ & 0.92 \\
C4-C7 & $9(2)$ & $1(0)$ & 0.31 \\
C7-Th1 & $3(0)$ & $1(0)$ & 0.98 \\
\hline
\end{tabular}

\section{Follow-up process chart}

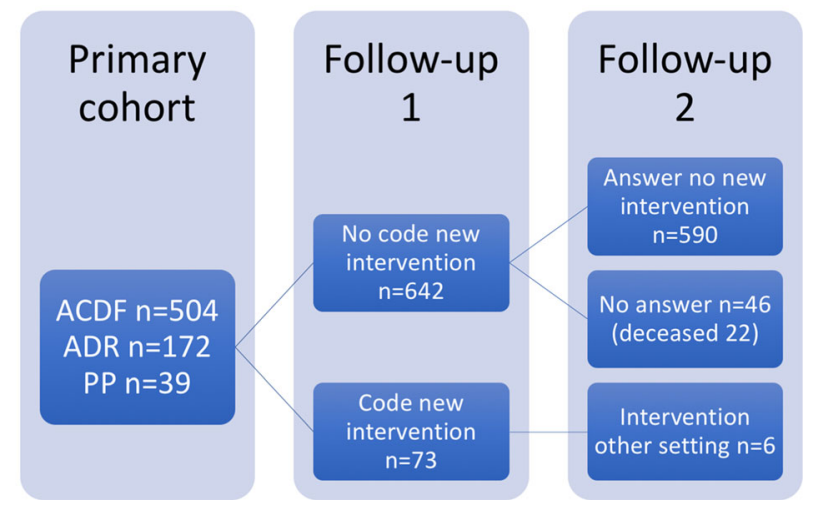

Fig. 1 Follow-up of the cohort

sample $t$ test for continuous data. Odds ratio with $95 \%$ confidence interval was calculated for differences between groups. A $p$ level less than 0.05 was regarded as statistically significant. SPSS version 23 was used for all calculations.

\section{Results}

The first follow-up resulted in 73 patients with a code for secondary intervention at the initial setting. Of the remaining 642 patients, answers were received from 532 by letter and 64 by telephone. Of these, six patients reported at least one second intervention at other settings, and in total, 79 patients had undergone a second intervention. Followup was registered in 669 of the initially 715 included patients (94\%). Of the remaining 46, 22 patients were reported deceased, while 24 could not be reached (Fig. 1). In the group of deceased patients, relatives could not confirm second cervical intervention in any case. As this was second hand information, this group was regarded as a loss to follow-up. 14 (2\%) patients were registered with more than one reoperation. The proportion of reoperated patients was 50/504 (10\%) in the ACDF group, 27/172 (15\%) in the ADR group, and 2/39 (5\%) in the PP group. Average time between the first operation and the second was 35.3 months. The reasons for reoperation differed between the groups and the second procedure solution was to some extent linked to the initial procedure (Table 4). Comparison between the groups ADR and ACDF regarding rates of reoperation showed OR 1.7 (CI 1.06-2.8) which was a statistically significant higher rate for ADR, $p=0.03$. Reoperation rate at the index level was even higher for the ADR group, OR 5.1 (CI 2.4-10.7), $p<0.001$. Reoperation rate because of ASD was proportionally higher for ACDF within the group of reoperated patients, OR 3.1 (CI 1.1-8.6), $p=0.03$. When all the operated patients in both groups were compared for reoperation because of ASD, no statistically significant difference could be shown, $p=0.40$. There was a statistically significant difference in distribution of gender between the two reoperated groups with a higher proportion of women in the ADR group, $p=0.01$. The mean time span from first to second interventions also differed between the groups with a longer mean time span in the ADR group, however, not statistically significant (Table 5). The most common cause for second intervention in the ACDF group was ASD resulting in additional fusion (22 patients) or a complementary ADR (4 patients) resulting in a hybrid construction. Migration or instability of the implant was the most common cause in the ADR group and all patients were reoperated with extraction of the ADR and conversion to an ACDF. In six patients, there was a substantial osteolysis around the ADR implant resulting in a malalignment. The only way to solve this was to perform a corpectomy of the 
Table 4 Rates and reasons for reoperation in the $\mathrm{ACDF}$ and ADR groups, respectively

\begin{tabular}{lcll}
\hline Rates of reoperation in respective group & ACDF $(n=50 / 504)$ & ADR $(n=27 / 172)$ & $p$ level $(0.03)$ \\
\hline Adjacent segment disease & $26(52 / 5)$ & $7(26 / 4)$ & $0.03 / 0.40$ \\
Migration of implant, osteolysis & $7(14 / 1)$ & $19(70 / 11)$ & $<0.01 /<0.01$ \\
Pseudarthrosis & $5(10 / 1)$ & n.a. & \\
Remaining neural compression & $10(20 / 2)$ & $0(0 / 0)$ & $0.44 / 0.31$ \\
Postoperative hematoma & $2(4 / 0)$ & $1(4 / 0)$ & $0.72 / 0.56$ \\
\hline
\end{tabular}

Figures within brackets show $\%$ of reoperation within group and whole group, respectively. $p$ levels are shown for comparison within reoperation of group/whole group
Table 5 Comparison of mean age (SD), distribution of gender, number of surgical levels, and mean time interval (SD) between index operation and second operation in the reoperation ACDF and ADR groups

\begin{tabular}{llll}
\hline & $\operatorname{ACDF}(n=50)$ & $\operatorname{ADR}(n=27)$ & $p$ level \\
\hline Age & $49.8(7.8)$ & $49.2(8.9)$ & 0.7 \\
Men/female & $30 / 20$ & $8 / 19$ & 0.01 \\
1 Level/2 level & $32 / 18$ & $18 / 9$ & 0.6 \\
Time interval (months) & $33(26)$ & $50(44)$ & 0.1 \\
\hline
\end{tabular}

damaged vertebrae after extraction of the ADR, and then to restore alignment with a two-level fusion (Fig. 2a-c). ASD in the ADR group was treated with either ADR (4 patients) or extraction of the ADR and conversion to ACDF at both levels (3 patients). Infection as a contributing factor for reoperation could only be established in one case with migration of implant following ACDF. In reoperated patients with ADR, infection was not found in any case, even though tissue samples for bacteria culture were taken during surgery. Severe dysphagia was reported in 18 patients $(23 \%)$ during the first postoperative period. No patient was reported with infection or severe neurological damage after secondary surgery.

\section{Discussion}

Conducting studies on complications and frequencies of secondary surgeries can be problematic from two aspects: the need for sufficiently large materials to detect rare events and to get reliable data. To obtain sufficient volumes of data, national registers can be used. However, in the Swespine, registration of cervical spine procedures was not started until 2006 and data were not initially reported from all settings performing cervical spine surgery. Furthermore, the long-term follow-up rates in registers tend not to be satisfactory and may lead to problems with too large numbers of loss of patients. In a study by Aghayev et al., 5-year follow-up of ADR in the SwissSpine register was only $64.8 \%$ [18]. The retrospective study design is not suitable for research questions requiring baseline data, but may have an advantage for long-term follow-up studies of complications. The follow-up rates of $94 \%$ in this study are higher and with more reliable data than we could get from the Swespine register. Previous studies comparing advert events and secondary surgeries between ACDF and ADR have during the last decade been presented in randomized trials and meta-analyzes with most articles reporting fewer secondary interventions in the ADR groups. The randomized controlled trials are predominantly industry sponsored investigational device exemption (IDE) studies with the intention to get FDA approval for the device in the US. Randomized trials with the primary intention to compare outcome between two different treatments may not be the best study design to evaluate rare events as reoperations. Sponsorship also might lead to a bias in decision making in secondary interventions [19-22]. Common reasons for secondary surgeries after ACDF in most randomized trials are pseudarthrosis and ASD. In this study, ASD was also the most common reason for a new intervention in the ACDF group, while intervention for pseudarthrosis was less than $1 \%$ which is lower than found in another retrospective study of 672 patients [23], but consistent with other publications $[24,25]$. A majority of patients in this cohort were treated with iliac crest bone and plating which might create better conditions for healing than alternative methods [26-28]. It should also be pointed out that pseudarthrosis could be a difficult diagnosis to establish as there is no sufficiently accurate radiological method to ensure very small movements in non-healed segments [29, 30]. Patients in this cohort who were reoperated because of pseudarthrosis were diagnosed with $\mathrm{CT}$ after a combination of suspected non-healing on plain $\mathrm{x}$-rays and continuous pain reported by the patient. The possibility that patients without severe symptoms, and thus not examined with CT, may have had a non-healed fusion can, therefore, not be ruled out. Despite a quite large number of patients operated with iliac crest bone in this cohort, no patient was reoperated due to complications at donor site. Reoperation rate because of ASD in this study was 5\% in the ACDF group with a follow-up time varying from 0 to 15 years. This is lower than reported in other literature. In a retrospective study by Lee et al., 1038 patients were analyzed regarding 
a

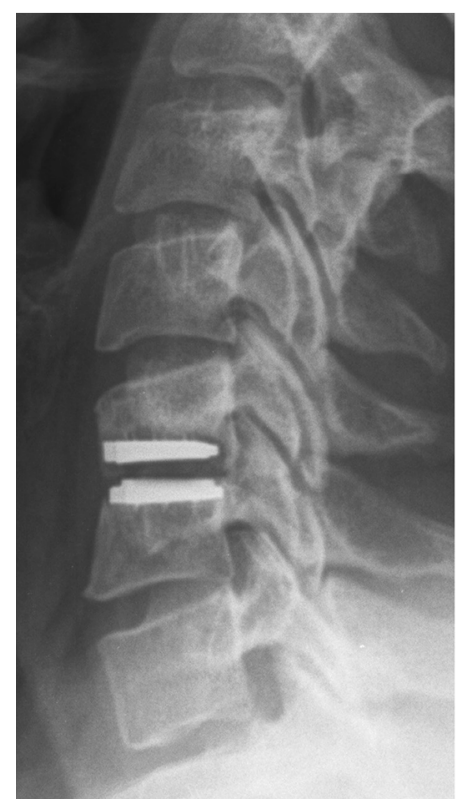

b

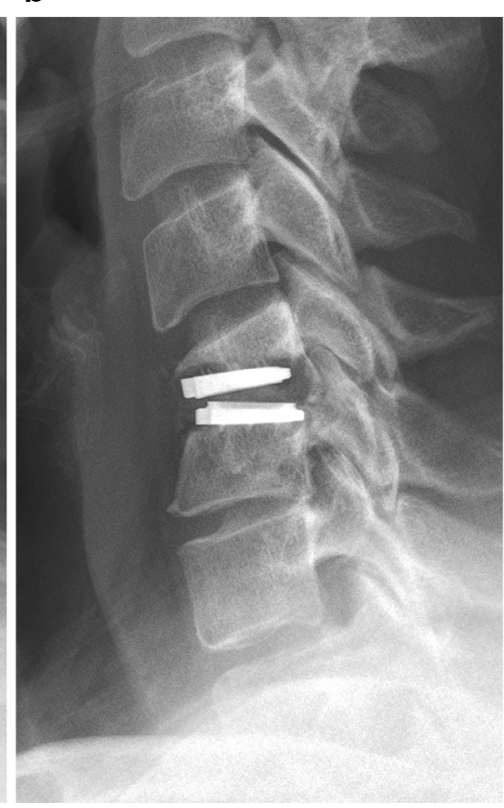

c

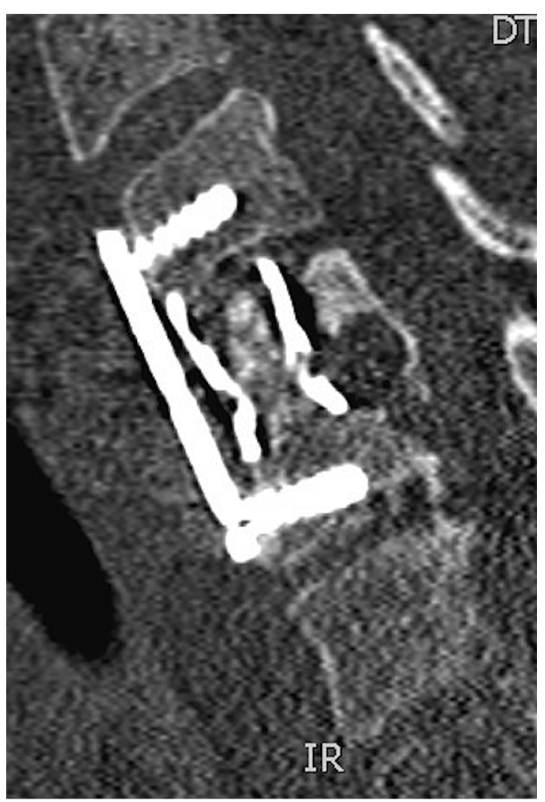

Fig. 2 a Lateral plain X-ray of a discover artificial disc at level C5C6 24 months after surgery. Subsidence and incipient osteolysis around the upper component of the implant can be seen but no severe symptoms presented by the patient. b Same patients as Fig. 2a but 52 months after initial surgery. The patient complains of severe neck

reoperation because of ASD and they found a relatively constant rate of 2.4\%/year and that smoking and female gender increased the risk and that more than two surgical levels decreased the risk for reoperation because of ASD [31]. In the present study, complete data for smoking were not available, why the impact of smoking could not be analyzed. Another study comparing reoperations for ASD in a cohort of patients outside RCTs with reoperation rates of patients inside the RCTs, and found a lower rate of $2.1 \%$ within 2 years [10]. Rates of reoperations because of ASD in this study were not statistically different between ACDF and ADR groups $(p=0.40)$, consistent with a meta-analysis showing no significant statistical difference between groups [32]. Ten patients in the ACDF group were reoperated because of the remaining neural compression and in most patients because of posterior pathology in the facet joints. This may reflect that patients in the ACDF group had more advanced degenerative changes than the patients in the ADR group, in which no patient was reoperated because of the same reason. Reoperation because of infection could be established in one patient who was treated with an ACDF. The anterior approach for cervical spine surgery is known for low infection rates and infection is seldom a reason for readmission [33]. The cohort in this study was followed for at least 5 years with a follow-up of 94\% and showed a statistically significant difference in rates of reoperations in total, advantageous for ACDF. This pain and X-ray shows severe osteolysis of the C5 vertebrae. An increasing kyphosis in the segment can also be noted. $\mathbf{c}$ CT of same patient after extraction of ADR and reconstruction with a two-level fusion done with a titanium mesh cage and additional plating

finding is deviant to results from most previously published RCTs and meta-analyzes showing lower rates of reoperations in the ADR groups [34-38]. The results in our study are supported by a study presented by Nandyala et al. in 2014. They used a nationwide inpatient sample database in the US with data from more than 180,000 patients, found revision rates for $\mathrm{ACDF}$ and $\mathrm{ADR}$ of 2.0 and $7.7 \%$, respectively, for one- and two-level surgeries during the years 2002-2011. They also found that revision surgery of ADR was associated with higher incidence of postoperative infection and greater length of stay [11]. The majority of patients in the ADR group in the present study were reoperated because of implant migration and/or instability, which is consistent with the results from a previous biomechanical in vivo CT study [39]. It must be pointed out that biomechanical characteristics may vary between different brands and designs of ADRs, and thus, the data in this study are not completely generalizable [40]. We cannot with this study point out certain risk factors for reoperation after treatment with ADR, event though we found that women were overrepresented in the group of patients who had undergone a second intervention in the ADR group. This might be a finding that could be associated with gender differences in bone morphology, but needs to be investigated further [41]. Evaluation of bone mineral density was not performed routinely in this cohort, and therefore, no analysis of association to reoperation rate 
could be done. There are several limitations with a retrospective study comparing different cohorts of patients as they might differ substantially in demographics and baseline data. There is also a risk for skewness between the groups depending on inclusion bias. As we in this study focused on reoperation following different surgical techniques, no conclusions can be made regarding patient reported outcomes. It can be argued that reoperation is not a good outcome measure and that decision making for this intervention may vary considerably between different surgeons. On the other hand, it is a dichotomous variable, also preceded by new symptoms and radiological findings that could not be neglected. Secondary surgical cervical spine interventions are associated with higher risk for complications, e.g., dysphagia, infection, and neurological damage, and must as far as possible be avoided.

\section{Conclusion}

In this cohort, we found an increased rate of secondary surgical intervention after initial surgery with cervical artificial disc replacement. No difference in surgical intervention for adjacent segment disease was found between the different primary surgical techniques. Patients initially treated with disc replacement also showed an increased risk for revision surgery at the index level. These findings indicate that disc replacement does not protect against adjacent level pathology, but instead may give rise to more implant-related problems.

Acknowledgements Thanks to Margareta Ekström at Stockholm Spine Center for invaluable help with handling of data.

\section{Compliance with ethical standards}

Conflict of interest statement None of the authors has any potential conflict of interest.

Open Access This article is distributed under the terms of the Creative Commons Attribution 4.0 International License (http://crea tivecommons.org/licenses/by/4.0/), which permits unrestricted use, distribution, and reproduction in any medium, provided you give appropriate credit to the original author(s) and the source, provide a link to the Creative Commons license, and indicate if changes were made.

\section{References}

1. Hilibrand AS, Carlson GD, Palumbo MA et al (1999) Radiculopathy and myelopathy at segments adjacent to the site of a previous anterior cervical arthrodesis. J Bone Jt Surg Am 81:519-528

2. Hilibrand AS, Robbins M (2004) Adjacent segment degeneration and adjacent segment disease: The consequences of spinal fusion? Spine J 4:190S-194S
3. Goffin J, Geusens E, Vantomme N et al (2004) Long-term followup after interbody fusion of the cervical spine. J Spinal Disord Tech 17:79-85

4. Ishihara H, Kanamori M, Kawaguchi Y et al (2004) Adjacent segment disease after anterior cervical interbody fusion. Spine $\mathrm{J}$ 4:624-628. doi:10.1016/j.spinee.2004.04.011

5. Chang KE, Pham MH, Hsieh PC (2017) Adjacent segment disease requiring reoperation in cervical total disc arthroplasty: a literature review and update. J Clin Neurosci 37:20-24. doi:10. 1016/j.jocn.2016.10.047

6. Blumenthal SL, Ohnmeiss DD, Guyer RD, Zigler JE (2013) Reoperations in cervical total disc replacement compared with anterior cervical fusion: results compiled from multiple prospective food and drug administration investigational device exemption trials conducted at a single site. Spine (Phila Pa 1976) 15(38):1177-1182. doi:10.1097/BRS. 0b013e31828ce774

7. Zigler JE, Delamarter R, Murrey D et al (2013) ProDisc-C and anterior cervical discectomy and fusion as surgical treatment for single-level cervical symptomatic degenerative disc disease: fiveyear results of a Food and Drug Administration study. Spine (Phila Pa 1976) 38:203-209. doi:10.1097/BRS. 0b013e318278eb38

8. Phillips FM, Geisler FH, Gilder KM et al (2015) Long-term outcomes of the US FDA IDE prospective, randomized controlled clinical trial comparing PCM cervical disc arthroplasty with anterior cervical discectomy and fusion. Spine (Phila Pa 1976) 40:674-683. doi:10.1097/BRS.0000000000000869

9. Loumeau TP, Darden BV, Kesman TJ et al (2016) A RCT comparing 7-year clinical outcomes of one level symptomatic cervical disc disease (SCDD) following ProDisc-C total disc arthroplasty (TDA) versus anterior cervical discectomy and fusion (ACDF). Eur Spine J. doi:10.1007/s00586-016-4431-6

10. Singh K, Phillips FM, Park DK et al (2012) Factors affecting reoperations after anterior cervical discectomy and fusion within and outside of a Federal Drug Administration investigational device exemption cervical disc replacement trial. Spine J 12:372-378. doi:10.1016/j.spinee.2012.02.005

11. Nandyala SV, Marquez-Lara A, Fineberg SJ, Singh K (2014) Comparison of revision surgeries for one- to two-level cervical TDR and ACDF from 2002 to 2011. Spine J 14:2841-2846

12. Mehren C, Suchomel P, Grochulla F et al (2006) Heterotopic ossification in total cervical artificial disc replacement. Spine (Phila Pa 1976) 31:2802-2806

13. Tortolani PJ, Cunningham BW, Eng M et al (2007) Prevalence of heterotopic ossification following total disc replacement. A prospective, randomized study of two hundred and seventy-six patients. J Bone Jt Surg Am 89:82-88

14. Fan $\mathrm{H}, \mathrm{Wu} \mathrm{S}, \mathrm{Wu} \mathrm{Z}$ et al (2012) Implant failure of Bryan cervical disc due to broken polyurethane sheath: a case report. Spine (Phila Pa 1976) 37:E814-E816

15. Brenke C, Schmieder K, Barth M (2015) Core herniation after implantation of a cervical artificial disc: case report. Eur Spine J 24:536-539

16. Viezens L, Schaefer C, Beyerlein J et al (2013) An incomplete paraplegia following the dislocation of an artificial cervical total disc replacement. J Neurosurg Spine 18:255-259

17. Svedmark P, Lundh F, Németh G et al (2011) Motion analysis of total cervical disc replacements using computed tomography: preliminary experience with nine patients and a model. Acta Radiol 52:1128-1137. doi:10.1258/ar.2011.110230

18. Aghayev E, Baerlocher C, Sgier F et al (2012) Five-years results of cervical disc prostheses in the Swiss spine registry. Eur Spine J 21:S297-S298. doi:10.1007/s00586-012-2269-0

19. Lexchin J (2012) Sponsorship bias in clinical research. Int J Risk Saf Med 24:233-242. doi:10.3233/JRS-2012-0574 
20. Cher DJ, Capobianco RA (2015) Spine device clinical trials: design and sponsorship. Spine J 15:1133-1140. doi:10.1016/j. spinee.2015.01.027

21. Bero L (2013) Industry sponsorship and research outcome. JAMA Intern Med 173:580. doi:10.1001/jamainternmed.2013. 4190

22. Bhandari M, Busse JW, Jackowski D et al (2004) Association between industry funding and statistically significant pro-industry findings in medical and surgical randomized trials. CMAJ 170:477-480

23. van Eck CF, Regan C, Donaldson WF et al (2014) The revision rate and occurrence of adjacent segment disease after anterior cervical discectomy and fusion: a study of 672 consecutive patients. Spine (Phila Pa 1976) 39:2143-2147. doi:10.1097/BRS. 0000000000000636

24. Guppy KH, Harris J, Paxton LW et al (2015) Reoperation rates for symptomatic nonunions in anterior cervical fusions from a National Spine Registry. Spine (Phila Pa 1976) 40:1632-1637. doi:10.1097/BRS.0000000000001085

25. Shriver MF, Lewis DJ, Kshettry VR et al (2015) Pseudoarthrosis rates in anterior cervical discectomy and fusion: a meta-analysis. Spine J 15:2016-2027. doi:10.1016/j.spinee.2015.05.010

26. Malloy KM, Hilibrand AS (2002) Autograft versus allograft in degenerative cervical disease. Clin Orthop Relat Res (394):27-38

27. Suchomel P, Barsa P, Buchvald P et al (2004) Autologous versus allogenic bone grafts in instrumented anterior cervical discectomy and fusion: a prospective study with respect to bone union pattern. Eur Spine J 13:510-515. doi:10.1007/s00586-003-0667-z

28. Wright IP, Eisenstein SM (2007) Anterior cervical discectomy and fusion without instrumentation. Spine (Phila Pa 1976) 32:772-774. doi:10.1097/01.brs.0000258846.86537.ad (discussion 775)

29. Hipp JA, Reitman CA, Wharton N (2005) Defining pseudoarthrosis in the cervical spine with differing motion thresholds. Spine (Phila Pa 1976) 30:209-210. doi:10.1097/01.brs. 0000151011.32573.f1

30. Ghiselli G, Wharton N, Hipp JA et al (2011) Prospective analysis of imaging prediction of pseudarthrosis after anterior cervical discectomy and fusion: computed tomography versus flexionextension motion analysis with intraoperative correlation. Spine (Phila Pa 1976) 36:463-468. doi:10.1097/BRS. 0b013e3181d7a81a

31. Lee JC, Lee S, Peters C, Riew KD (2014) Risk-factor analysis of adjacent-segment pathology requiring surgery following anterior, posterior, fusion, and nonfusion cervical spine operations: survivorship analysis of 1358 patients. J Bone Jt Surg Am 96:1761-1767

32. Verma K, Gandhi SD, Maltenfort M et al (2013) Rate of adjacent segment disease in cervical disc arthroplasty versus single-level fusion: meta-analysis of prospective studies. Spine (Phila $\mathrm{Pa}$ 1976) 38:2253-2257. doi:10.1097/BRS.0000000000000052

33. Samuel AM, Fu MC, Toy JO et al (2016) Most 30-day readmissions after anterior cervical discectomy and fusion are not due to surgical site-related issues. Spine (Phila Pa 1976) 41:1801-1807. doi:10.1097/BRS.0000000000001775

34. Gao F, Mao T, Sun W et al (2015) An updated meta-analysis comparing artificial cervical disc arthroplasty (CDA) versus anterior cervical discectomy and fusion (ACDF) for the treatment of cervical degenerative disc disease (CDDD). Spine (Phila Pa 1976) 40:1816-1823. doi:10.1097/BRS.0000000000001138

35. Yin S, Yu X, Zhou S et al (2013) Is cervical disc arthroplasty superior to fusion for treatment of symptomatic cervical disc disease? A meta-analysis. Clin Orthop Relat Res 471:1904-1919. doi:10.1007/s11999-013-2830-0

36. Zou S, Gao J, Xu B et al (2016) Anterior cervical discectomy and fusion (ACDF) versus cervical disc arthroplasty (CDA) for two contiguous levels cervical disc degenerative disease: a metaanalysis of randomized controlled trials. Eur Spine J. doi:10. 1007/s00586-016-4655-5

37. Jackson RJ, Davis RJ, Hoffman GA et al (2016) Subsequent surgery rates after cervical total disc replacement using a Mobi-C cervical disc prosthesis versus anterior cervical discectomy and fusion: a prospective randomized clinical trial with 5-year followup. J Neurosurg Spine 24:734-745. doi:10.3171/2015.8. SPINE15219

38. Delamarter RB, Zigler J (2013) Five-year reoperation rates, cervical total disc replacement versus fusion, results of a prospective randomized clinical trial. Spine (Phila Pa 1976) 38:711-717. doi:10.1097/BRS.0b013e3182797592

39. Skeppholm M, Svedmark P, Noz ME et al (2015) Evaluation of mobility and stability in the Discover artificial disc: an in vivo motion study using high-accuracy 3D CT data. J Neurosurg Spine 23:383-389. doi:10.3171/2014.12.SPINE14813

40. Faizan A, Goel VK, Garfin SR et al (2012) Do design variations in the artificial disc influence cervical spine biomechanics? A finite element investigation. Eur Spine J 21:S653-S662

41. Carson JA, Manolagas SC (2015) Effects of sex steroids on bones and muscles: similarities, parallels, and putative interactions in health and disease. Bone 80:67-78. doi:10.1016/j.bone.2015.04. 015 